\title{
DISCRIMINATION-RELATED STRESS, BLOOD PRESSURE AND EPSTEIN-BARR VIRUS ANTIBODIES AMONG LATIN AMERICAN IMMIGRANTS IN OREGON, US
}

\author{
HEATHER H. MCCLURE*†, CHARLES R. MARTINEZ Jr*, \\ J. JOSH SNODGRASS $\dagger$, J. MARK EDDY*, ROBERTO A. JIMÉNEZ†, \\ LAURA E. ISIORDIA† AND THOMAS W. MCDADE
}

*Oregon Social Learning Center, Eugene, OR, USA, †Department of Anthropology, University of Oregon, Eugene, OR, USA, \$Farmworker Housing Development Corporation, Woodburn, OR, USA and §Department of Anthropology and Institute for Policy Research, Northwestern University, Evanston, IL, USA

\begin{abstract}
Summary. Perceived discrimination has been linked to poor health outcomes among ethnic and racial minorities in the United States, though the relationship of discrimination-related stress to immigrant health is not well understood. This article reports findings from a preliminary study that examined blood pressure and Epstein-Barr virus antibody levels in relation to selfreported indicators of stress, acculturation and social support among 79 adult immigrant Latino farm workers in Oregon, US. Findings show that increases in discrimination-related stress predicted elevated systolic blood pressure (SBP) and Epstein-Barr virus antibody levels among male participants. Though female participants reported similar levels of discrimination stress, this perceived stress was not reflected in biological measures. Among women, greater English language engagement was linked to higher SBP, and more years in the US was associated with higher diastolic blood pressure. Study results suggest that male and female immigrants' physiological responses to stress may be influenced in distinctive ways by processes of adjustment to life in the US. If replicated, the finding that discrimination stress predicts elevated SBP may have clinical and public health implications given that elevated SBP is an established risk factor for cardiovascular disease.
\end{abstract}

\section{Introduction}

Persistent racial and ethnic disparities in the United States have been shown to diminish the overall life prospects, quality of life and life expectancy of many ethnic and/or racial minority populations (Institute of Medicine, 2002; Williams \& Jackson, 2005; Landrine et al., 2006). Numerous studies have shown that these 
disparities - such as disproportionate disease risk among minority populations when compared with the white population - are not only the result of less access to health care and prevention services by minority groups, but are also related to perceptions of racial or ethnic discrimination as a type of stressful life experience (Harrell et al., 2003; Williams et al., 2003; Dressler et al., 2005; Ryan et al., 2006).

Discrimination-related stress has been shown to correlate with biological measures such as elevated systolic and diastolic blood pressure (SBP and DBP, respectively; Dressler, 1990; James et al., 1994; Ryan et al., 2006). Chronic psychosocial stress, such as that related to discrimination, has also been linked to elevated Epstein-Barr virus (EBV) antibody levels indicative of reduced cell-mediated immune function (Kiecolt-Glaser et al., 1984, 1994; Glaser et al., 1985). There is scant research among immigrants, however, that utilizes biological as well as self-report measures to examine the links among psychosocial stress in general, perceived discrimination in particular, and physical health (Finch \& Vega, 2003; Ryan et al., 2006); even fewer studies take into account stressors related to processes of adjustment to life in the United States (acculturation). Little is known about whether diverse psychosocial stressors among immigrants - including discrimination and acculturative stressors trigger distinct physiological responses, such as elevated blood pressure or EBV antibody levels, or both. A clearer understanding of the relationships between chronic stressors and diverse physiological pathways may ultimately offer insights into links between social determinants of immigrant health and increased susceptibility to illness, including chronic disease.

\section{Latinos in the United States}

Despite the size of the Latino population in the United States (15\% of the nation's population, and the largest ethnic/racial minority group; US Census Bureau, 2008a), little is known about stress and health among the $40 \%$ of Latinos in the US who are foreign born (Pew Hispanic Center, 2007). In Oregon, Latinos also comprise the largest minority group $(10 \%)$, though like other states that are sites of rapid immigrant population growth, Oregon has limited recent experience with large influxes of immigrant newcomers. Such rapid growth, when combined with Englishlanguage-dominant institutions and systems that may be unprepared to address the needs of a culturally pluralistic population, can contribute to intense stress for Latino adults and families (Martinez et al., 2008; Farquhar et al., 2008). Latino immigrants' contact with dominant society may also bring its share of discriminatory experiences (Finch \& Vega, 2003; Pérez et al., 2008), the physical health effects of which are just beginning to be investigated.

\section{Acculturation and immigrant health}

Acculturation is a multidimensional construct that describes phenomena resulting from continuous contact between groups of individuals from different cultures, including subsequent changes in the cultural patterns of one or both groups (Berry, 1998). Because acculturation is multidimensional, including such factors as language proficiency, language use, nativity, culture-related behavioural preferences and ethnic 
identity, among others, no consistent or uniform definition or measurement strategy has been established in the literature (Cabassa, 2003; Carter-Pokras \& Bethune, 2009; Thomson \& Hoffman-Goetz, 2009a, b). Though a multidimensional measurement of assessment is considered the 'gold standard', the present study focused on two elements - English language engagement and time in residence (TR) - in order to minimize participant burden. These specific variables also were selected to assess aspects of acculturation that are particularly salient to the context of Oregon where the burden of communication with monolingual English speakers and institutions is borne predominantly by immigrants. In addition, these variables have been shown to account for a large percentage of the variance in acculturation scores using standardized instruments (Marín \& Marín, 1991; Portes \& Rumbaut, 2001). Acculturation also can serve as a marker for other psychosocial processes (e.g. family support and socioeconomic status) that should be measured as potential explicating variables linking discrimination stress among immigrants with health change (Escobar \& Vega, 2000; Lara et al., 2005). For instance, more time in residence and greater English language engagement tend to relate to reduced family support (Vega \& Gil, 1999; Pantin et al., 2007) and to higher socioeconomic status (Mason, 2004), two variables shown to relate to physiological responses to psychosocial stress exposure, including discrimination.

\section{Discrimination}

Contrada and colleagues (2001) define ethnic discrimination as unfair treatment received because of one's 'ethnicity', referring to various groupings of individuals based on culture of origin (Brondolo et al., 2009b). Numerous studies have illustrated the ways in which discrimination and stigma, social processes linked to the reproduction of inequality and exclusion (Paradies, 2006), are an intrinsic part of life in the US and affect minority groups on a daily basis (Szalacha et al., 2003). Of relevance to the current study is evidence that perceived discrimination varies by immigrants' nativity and age upon arrival in the US (Finch et al., 2000; Dominguez et al., 2009). Pérez and colleagues (2008) observed that US-born Latinos and foreign-born Latinos who arrived in the US at six years of age or younger were more likely to report discrimination than their less-acculturated counterparts who arrived in the US as adolescents or young adults.

Discrimination based on race and ethnicity has also been linked to lower socioeconomic status (SES) within various contexts (Finch et al., 2000). Low SES, in turn, has been associated in several studies with chronic activation of the stress response (Lupien et al., 2000; Kunz-Ebrecht et al., 2004), greater health risks and poorer health across the lifespan (Wadsworth \& Achenbach, 2005). As extensive evidence exists of the corrosive effects of poverty on the ability to maintain good health (e.g. Marmot, 2004; Steffen, 2006; Wadsworth et al., 2008), the present study investigates the potential interactive effects of SES and discrimination stress for changes in immigrants' physiology and health.

\section{Discrimination and blood pressure}

The negative mental health effects of prejudice and stigma are well-documented, though the links between perceived discrimination and poor physical health are less 
definitive (Harrell et al., 2003; Williams et al., 2003; Din-Dzietham et al., 2004). The few studies on the relationship between discrimination and blood pressure among Latinos in the US show mixed results. In one of the earliest studies, James and colleagues found a positive correlation between discrimination and blood pressure in a majority Latino sample of workers (James et al., 1994). A decade later, Ryan and colleagues (2006) found that perceived discrimination experienced by Latino immigrants was significantly associated with higher SBP, a well-recognized risk factor for cardiovascular disease (Kannel et al., 1996; Lenfant et al., 2003). Diastolic blood pressure (DBP), however, was unrelated to discrimination, and the authors posited that SBP may serve as a better marker for hypertension and related illnesses than DBP (Black, 1999). Brondolo and colleagues (2008), in their study of ambulatory blood pressure and discrimination among US-born Latinos and black adults, observed that perceived racism was positively associated with nocturnal ambulatory blood pressure even when controlling for personality factors and SES.

In contrast, Krieger and colleagues (2008) detected no significant relationships between unfair treatment and SBP, a similar finding to that of the Study of Women's Health Across the Nation (Brown et al., 2006). Though SWAN researchers found racial/ethnic differences in blood pressure among middle-aged women, with Latinas and African-American women having the highest measured blood pressure of all groups, high levels of perceived unfair treatment were not correlated with elevated SBP or DBP for women of any racial/ethnic group. Finally, in a meta-analysis that drew on studies of acculturation and blood pressure conducted around the world, Steffen and colleagues (2006) found that men's blood pressure was more negatively affected by acculturation than women's. These researchers attributed this difference to context, citing that male immigrants were more likely to be exposed to workplacebased stressors, while female immigrants were more likely to remain in the home, interacting with a network of culturally similar women. Steffen and colleagues' valuable review suggests as a next step the consideration of potential effects on blood pressure of distinct aspects of acculturation (e.g. nativity, language use and TR) and covariates such as SES and family support.

\section{Psychosocial stress and immune function}

Over the past two decades, EBV antibody levels have been applied as a biomarker of chronic psychosocial stress (McDade et al., 2000a; Panter-Brick et al., 2008). The Epstein-Barr virus is a ubiquitous herpes virus for which $80-90 \%$ of adults in the US test positive by the age of 40 (Jones \& Straus, 1987), with even higher prevalence rates estimated in the developing world (McDade et al., 2000a). Once infected, individuals harbour the virus for life but adequate cell-mediated immune function maintains the virus in a latent state and most adults infected with EBV are clinically asymptomatic (Henle \& Henle, 1982). Stress-induced immunosuppression, however, allows EBV to reactivate, which may trigger an antibody response (Glaser et al., 1991); an increase in levels of antibodies against EBV, therefore, is interpreted as a reduction in aspects of cell-mediated immune function. Researchers have found elevations in EBV antibody levels among individuals in poor quality marriages (Kiecolt-Glaser et al., 1993, 1994), caregivers for a family member with Alzheimer's disease (Kiecolt-Glaser 
et al., 1987), and Samoan adolescents and indigenous Siberian adults exposed to Westernizing influences (McDade et al., 2000b; Sorensen et al., 2009). Research in the US and internationally also indicates important gender differences, with higher levels of psychosocial stress and depression corresponding with elevated EBV antibody levels among women and adolescent girls (Kiecolt-Glaser et al., 1993; McDade \& Worthman, 2004; Panter-Brick, et al., 2008).

There is compelling evidence that stress-induced alterations in immune function are causally related to a range of disease outcomes (McDade, 2007), including wound healing (Kiecolt-Glaser et al., 1995; Marucha et al., 1998) and rheumatoid arthritis (Affleck et al., 1997). Because of EBV's reliability as a marker for chronic psychosocial stress, at least one population-based study in the US (e.g. the National Longitudinal Study of Adolescent Health) has incorporated it (McDade et al., 2007).

Most investigations into psychosocial stress have relied upon perceived or reported variables as estimates of exposure to stressors. The present study also uses multiple biological markers of chronic psychosocial stress, including blood pressure and EBV antibodies, to better understand the complex pathways linking stress exposure (related to unfair treatment in particular) to physiological change and, ultimately, to health status (Brondolo et al., 2009a). In addition, the current study investigates elements of acculturation in relation to reported discrimination stress exposure and immigrant physiological measures. Though acculturation has been widely recognized as a potential stressor within foreign-born populations (Vega \& Gil, 1999; Martinez, 2006), only a few studies address blood pressure and acculturative change among immigrants in the US (e.g. Jurkowski \& Johnson, 2005; Boeckner et al., 2006; Mainous et al., 2006). A similarly small number of studies have used biomarkers to investigate acculturative stress, and most of these were conducted outside the US and focused primarily on the health effects of economic development (e.g. Hanna, 1998; McDade, 2001; Bongard et al., 2002; Gustafsson et al., 2006; Snodgrass et al., 2007; Matheson et al., 2008). The present study helps to fill this gap by integrating biological as well as self-report measures to investigate what more might be learned about the influence of discrimination-related stress on immigrant health in the US, especially when variables such as SES, family support and aspects of acculturation (e.g. TR, English language engagement) are taken into account.

This study tested four main hypotheses:

(1) Higher acculturation, and lower SES and family support, are associated with higher reported discrimination stress among both women and men;

(2) Greater reported discrimination stress is associated with men's elevated SBP and DBP and is unrelated to women's blood pressure;

(3) Perceived discrimination is positively related to men and women's EBV antibody levels;

(4) Discrimination-related stress interacts with SES to predict elevations in SBP and DBP among men, and higher EBV antibody levels among men and women.

\section{Methods}

The study employed a community-based participatory research approach involving collaboration with a well-respected community-based organization that provides 
housing and social services to farm workers. This organization's farm worker housing complexes are located in three towns in the Willamette Valley, a rich agricultural region known for its fruits, vegetables, nurseries and vineyards.

\section{Sample recruitment}

The target sample of 80 individuals was drawn from farm worker residents living in housing complexes in one of two Willamette Valley locations: (1) in a small rural community (population 8200), and (2) on the outskirts of one of Oregon's medium-sized cities (population 149,000). Study eligibility required that participants be adults (18 years or older) and, if female, were not pregnant. The community-based organization staff identified 105 potential participants during the recruitment phase. Recruitment efforts focused on word-of-mouth and direct person-to-person contacts, both of which have been shown to be effective recruitment strategies for Latino immigrants in this region (Harachi et al., 1997). Of potential participants, 90 residents were present on their scheduled day of assessment. Of these, five women were ineligible for the study (one woman was younger than 18, and four women were pregnant). Of 85 eligible individuals, 82 were successfully recruited and participated in both the health exam and interview phases of the assessment, yielding an overall participation rate of $96 \%$.

The sample for this study was drawn from a non-probability design as previous longitudinal studies have successfully relied on this approach to address significant challenges associated with traditional probability sampling methods with immigrant communities, especially those with a large proportion of undocumented members, such as in Oregon, who may not be included in census counts or public-access information databases. This design also was informed by authors' prior experience with recruitment challenges due to public commentary portraying Latino immigrants as criminal, coupled with recent dramatic increases in detentions of immigrants in their workplaces and homes. This study relied solely upon recruiters who were Latina/o, native Spanish speakers, and foreign born, and recruited through trusted social networks. The reliance on a convenience sample has implications for the generalizability of the findings of this preliminary study (see Discussion below).

\section{Participants}

Analyses focused on 51 female and 28 male residents (18-69 years of age). Fifty-seven per cent were residents of a farm worker complex located in a rural area, and the remaining $43 \%$ lived in a residence on the outskirts of a mid-sized city. Ninety-seven per cent (77 participants) of the sample was born in Mexico, with the remaining two participants from Guatemala. Women averaged 33.9 years old $(\mathrm{SD}=10.4)$ and men averaged 37.0 years old $(\mathrm{SD}=12.2)$. Women immigrated to the US an average of 8.2 years prior to the study $(\mathrm{SD}=6.6)$ and men arrived 12.7 years prior $(\mathrm{SD}=10.1)$, with men significantly more likely to have lived in the US for more time than women $(p<0.05)$. There were no significant differences in the ages of women and men in the two study sites. About $54 \%$ of men and $63 \%$ of women had an 8 th grade education or less, with $26 \%$ of men and $11 \%$ of women completing high 
school or receiving post-secondary education. Ninety-three per cent of men and $45 \%$ of women were employed; an additional $36 \%$ of women reported they were homemakers. Heads of household reported an annual median household income of US $\$ 15,000$ to support an average household of five people $(\mathrm{SD}=1.5)$. Seventy-two per cent of participants reported having no health insurance, with $58 \%$ of uninsured respondents reporting they did not have a health provider they could consult if concerned about a health issue. Approximately $22 \%$ of the sample reported speaking mostly English at home.

\section{Assessment procedures}

On a single day, residents participated in a health assessment and responded to a 20-minute interview. All participants provided written consent prior to the assessment. All participants had fasted ( $>8$ hours) and were in a post-absorptive state. The health examination involved the measures of blood pressure, height and weight, total cholesterol and fasting glucose (see below). Blood spot samples were collected for later analyses of EBV antibodies and C-reactive protein (CRP; see below). C-reactive protein was used as a biomarker of current or recent infection to control for the potential impact of infection on immune function. Following the interview, participants received one-on-one health counselling and, when indicated, were referred to partner public health agencies for follow-up. All respondents were assessed in Spanish.

\section{Biological measures}

Stature and body mass were recorded using standard procedures (Lohman et al., 1988). Body mass index (BMI) was calculated as mass divided by height in metres squared $\left(\mathrm{kg} / \mathrm{m}^{2}\right)$. Regional fat distribution was assessed by waist circumference (WC) following standard procedures (National Institutes of Health, 2000; Ho et al., 2003).

Blood pressure measurements were collected using an Omron HEM-422CRLC manual inflation oscillometric blood pressure monitor (Vernon Hills, IL). For each participant, blood pressure was measured two separate times, taken at least 10 minutes apart, following standard practice; all blood pressure measurements were taken on the same visit and during the morning. The average of the two measurements was used in all analyses. Descriptive statistics were used to identify two SBP outliers and one DBP outlier (values were greater than two standard deviations from the mean) whose inclusion influenced the significance of correlations run with independent variables; these outliers were excluded from final analyses.

Whole blood spot samples were collected for subsequent laboratory analysis of CRP and EBV antibody levels. Following standard procedures (McDade et al., 2007), each participant had their finger pricked with a sterile disposable lancet; 2-5 drops of blood were then collected on standardized filter paper (No. 903; Whatman, Florham Park, NJ). Blood spot samples were then dried overnight, and were stored at $-80^{\circ} \mathrm{C}$ until laboratory analysis. Blood spot EBV antibody and CRP concentrations were measured using a high-sensitivity enzyme-linked immunosorbent assay (ELISA) protocol described elsewhere (McDade et al., 2000a). Assay validation indicated good 
sensitivity, precision and reliability. All participants were seropositive. Serum equivalent CRP concentrations, calculated through a conversion formula, were used to identify samples greater than $5.0 \mathrm{mg} / \mathrm{l}$ that were considered indicative of current infection (McDade, 2001); five individuals fitted this criterion and were excluded from statistical analyses. All laboratory analyses were performed in the Laboratory for Human Biology Research at Northwestern University.

\section{Interview}

The present study relied on a measurement strategy that has been extensively developed and refined for use with the Latino population by the Oregon Social Learning Center's Latino Research Team. Due to the brevity of the interview, specific items were drawn from a larger assessment battery that consistently and strongly relate to constructs of interest in the current study (e.g. perceived discrimination, acculturation, family support). The Latino Research Team assessment battery incorporates culturally specific and psychometrically validated standardized instruments (e.g. Perceived Discrimination [Kessler et al., 1999], Hispanic Stress Inventory for Immigrants [Cervantes, Padilla, \& Salgado de Snyder, 1990], and Hispanic Familism Scale [Sabogal et al., 1987]). The present study's questionnaire also included sociodemographic, health and food security items drawn from standardized instruments adapted for use with US Spanish-speaking populations in general (e.g. Harrison et al., 2003; National Health Interview Survey; National Center for Health Statistics, 2006), and with Mexican origin immigrant populations in particular (Villarejo \& McCurdy, 2008).

Though this study had little variance in occupation as all participants engaged in work on farms, vineyards or in canneries, income and education were used as proxies for different gradients of SES to discern its relationship to discrimination-related stress, and to biological measures of blood pressure and EBV. Separate analyses by sex relied upon either women's or men's educational levels, and personal income (for employed heads of household) or household income (for analyses including homemakers). In keeping with previous research (Gravlee et al., 2005), each of the variables for women and men's SES was further transformed into a dichotomous variable (for use in graphs only) through recoding the lower $50 \%$ of responses as 'lower SES', and the upper $50 \%$ of responses as 'higher SES'.

Time in residence is equal to the number of years and months a participant reported living in the US.

An English language orientation (ELO) factor score was created from three items to reflect respondents' engagement with English language practices (Cuellar et al., 1995). The first item asked respondents how much participants enjoy English language or American activities (e.g. music, TV or radio programmes, food) and had a 5-point Likert scale (1=don't enjoy at all, to 5=enjoy a lot). The second and third items asked how comfortable respondents feel speaking English and reading English ( $1=$ very uncomfortable, to $5=$ very comfortable). The acculturation factor created from these three items had factor loadings of 0.70 for enjoyment of English language activities, and 0.81 and 0.83 for comfort speaking English, and reading in English, respectively. The Kaiser-Meyer-Olkin (KMO) test of sampling adequacy was 0.637 
(considered acceptable); this factor explained $61.3 \%$ of observed variance. The ELO variable was further transformed into a two-part variable (for use in graphs only) to indicate those participants who have either less of an orientation toward English language activities (lower $50 \%$ of responses) or more of an orientation (upper $50 \%$ of responses).

Perceived discrimination was measured through a two-part question taken from the LRT's adapted Perceived Discrimination (Kessler et al., 1999) instrument, in which respondents were first asked whether they had been treated as if inferior because of their race, ethnicity, skin colour, language or nationality within the last three months. If no discriminatory event(s) occurred, participants selected ' $6=$ No', and if the event did occur, respondents were asked to rate on a 5-point scale the degree of stress they experienced due to the event(s) (1=not at all stressful, to $5=$ extremely stressful). A five-item scale was created by merging ' $6=$ No' with ' $1=$ not at all stressful' to create ' $1=$ no stress' to reflect participants who reported experiencing no discriminatory event or no stress related to discrimination; this five-item variable was used in all correlations. For use in graphs, the five-item variable was transformed into a dichotomous variable with 'no stress', and '2' to ' 5 ' recoded as 'stress'.

Family support was measured through responses to a single item from the Hispanic Familism Scale: 'When someone has problems s/he can count on help from his/her relatives'. Possible responses were on a Likert scale ranging from one to five ( $1=$ very much in agreement, to $5=$ very much in disagreement). This variable was reverse coded so that responses on the high end of the scale reflected high agreement with the statement.

\section{Analytic strategy}

Analyses were performed on males and females separately. Statistical analyses were performed using SPSS 13.0. Distributional assumptions were examined using Kolmogorov-Smirnov tests. To ensure a normal distribution for analysis purposes, EBV antibody values were $\log 10$-transformed and $\operatorname{logEBV}$ (EBV) was used in subsequent analyses. Descriptive statistics were used to identify one outlier whose inclusion did not influence the significance of correlations run with EBV and independent variables and was included in final analyses. Descriptive statistics for anthropometric data are presented in Table 1. Pearson's correlations were used to assess associations among EBV, SBP and DBP, and anthropometric variables by sex (Table 2). For both men and women, EBV was unrelated to age, BMI and waist circumference. BMI and waist circumference were positively related to SBP and DBP, a result in keeping with an established literature demonstrating strong relationships between body composition and blood pressure (Kaplan, 2005; smoking was unrelated to all biomeasure variables). As associations between waist circumference and the two blood pressure measures were substantially stronger than those between blood pressure and BMI (Table 2), waist circumference was selected in lieu of BMI as a covariate in partial correlations and multiple regressions in which SBP or DBP were dependent variables.

To test the final hypothesis, variables were created to analyse the interaction effects of discrimination-related stress ('inferior') and SES on the dependent variables 
Table 1. Descriptive statistics for age and anthropometric data ${ }^{a, b}$

\begin{tabular}{lcc}
\hline Measure & Females $(n=51)$ & Males $(n=28)$ \\
\hline Age (years) & $33.9(10.4)$ & $37.0(12.2)$ \\
Height $(\mathrm{cm})$ & $156.0(7.0)^{* * *}$ & $165.4(6.2)$ \\
Weight $(\mathrm{kg})$ & $70.6(12.7) \dagger$ & $76.5(15.1)$ \\
BMI $\left(\mathrm{kg} / \mathrm{m}^{2}\right)$ & $29.1(5.3)$ & $27.9(4.5)$ \\
WC $(\mathrm{cm})$ & $89.6(13.9)$ & $93.5(13.9)$ \\
EBV antibodies & $136.7(67.9)$ & $109.3(77.8)$ \\
SBP $(\mathrm{mmHg})$ & $109.3(13.8) \dagger$ & $114.6(10.9)$ \\
DBP $(\mathrm{mmHg})$ & $72.4(8.5)$ & $72.6(8.4)$
\end{tabular}

BMI: body mass index; WC: waist circumference; EBV: Epstein-Barr virus; SBP: systolic blood pressure; DBP: diastolic blood pressure.

${ }^{a}$ All values are represented as means and standard deviations.

${ }^{b}$ Differences between females and males are statistically different at $\dagger p<0.10 ; * * * p<0.001$.

${ }^{c}$ Excluding C-reactive protein (CRP) values greater than $5.0 \mathrm{mg} / \mathrm{l}$.

of EBV, SBP and DBP. Given the modest sample size, in order to have adequate power to conduct multiple regressions for the smallest cell sizes $(n=28$ for analyses involving men), interaction variables were computed through first creating separate $Z$-scores for men and women of the independent variables 'SES' and 'inferior'. Two interaction variables (one for each sex) were then created through multiplying the $Z$-scored 'inferior' by the Z-scored 'SES.' All multiple regressions contained the same control variables - age, waist circumference, inferior and SES - in addition to the interaction variable to analyse the effects of discrimination and SES on each physiological marker.

\section{Results}

Stress and EBV antibody levels

A larger share of women (43\%) than men $(35 \%)$ reported being treated as if inferior and being stressed by it, though the difference in women and men's discrimination-related stress was not significant. Differences in women and men's EBV antibody levels approached significance $(p=0.09)$. Bivariate correlations revealed that men's stress was positively correlated with higher EBV antibody levels, though the relationship only approached significance (Table 2). After adjusting for men's SES through a partial correlation, however, stress and EBV were shown to be unrelated $(r=0.31, p>0.10)$. English language orientation (ELO) showed a negative trend in relation to men's EBV (Table 3); this trend remained after adjusting for SES $(r=-0.37, p=0.07)$. Men's family support and TR were both unrelated to EBV, even after adding SES to the partial correlation as a potential confounder $(r=-0.20$, $p>0.10)$.

Among women, discrimination-related stress showed a negative trend in relation to EBV (Table 2); after controlling for SES in a partial correlation, this relationship 
Table 2. Correlation matrix for age, SES and sociocultural and measured variables by sex

\begin{tabular}{|c|c|c|c|c|c|c|c|c|c|c|c|}
\hline Variables & Age & SES & $\mathrm{TR}$ & Inferior & ELO & Support & BMI & WC & $\log \mathrm{EBV}$ & SBP & DBP \\
\hline \multicolumn{12}{|c|}{ Men } \\
\hline Age (years) & 1 & $0.49^{*}$ & $0.49 * *$ & -0.08 & -0.12 & 0.11 & $0.35^{\dagger}$ & 0.30 & 0.30 & $0.37^{\dagger}$ & $0.42 *$ \\
\hline $\mathrm{SES}^{\mathrm{a}}$ & & 1 & -0.14 & -0.28 & $0.36^{\dagger}$ & -0.04 & 0.03 & -0.07 & -0.20 & -0.30 & -0.12 \\
\hline TR (years) & & & 1 & 0.06 & 0.20 & 0.31 & 0.18 & 0.10 & 0.11 & 0.18 & 0.17 \\
\hline Inferior & & & & 1 & -0.08 & 0.23 & -0.06 & -0.03 & $0.36^{\dagger}$ & 0.26 & 0.01 \\
\hline ELO & & & & & 1 & 0.28 & -0.11 & -0.04 & $-0.37^{\dagger}$ & -0.04 & 0.001 \\
\hline Support & & & & & & 1 & 0.03 & 0.02 & -0.17 & -0.10 & -0.24 \\
\hline BMI $\left(\mathrm{kg} / \mathrm{m}^{2}\right)$ & & & & & & & 1 & $0.85^{* * *}$ & 0.30 & $0.45^{*}$ & $0.40 *$ \\
\hline $\mathrm{WC}(\mathrm{cm})$ & & & & & & & & 1 & 0.23 & $0.44^{*}$ & $0.41 *$ \\
\hline $\operatorname{logEBV}$ & & & & & & & & & 1 & $0.60 * * *$ & $0.46^{*}$ \\
\hline SBP (mmHg) & & & & & & & & & & 1 & $0.67 * * *$ \\
\hline DBP (mmHg) & & & & & & & & & & & 1 \\
\hline \multicolumn{12}{|c|}{ Women } \\
\hline Age (years) & 1 & $-0.32 *$ & 0.09 & 0.07 & -0.21 & -0.14 & $0.34 *$ & $0.41 * *$ & 0.14 & $0.48 * * *$ & $0.26^{\dagger}$ \\
\hline $\mathrm{SES}^{\mathrm{a}}$ & & 1 & $0.43^{* *}$ & -0.11 & $0.47 * * *$ & -0.07 & 0.03 & 0.01 & -0.10 & -0.02 & 0.05 \\
\hline TR (years) & & & 1 & 0.01 & $0.37 * *$ & -0.10 & $0.30 *$ & 0.20 & $0.27^{\dagger}$ & $0.27^{\dagger}$ & $0.36^{*}$ \\
\hline Inferior & & & & 1 & -0.09 & 0.03 & $0.24^{\dagger}$ & 0.13 & $-0.27^{\dagger}$ & 0.03 & -0.004 \\
\hline ELO & & & & & 1 & $-0.28^{\dagger}$ & 0.08 & 0.06 & -0.02 & 0.19 & 0.18 \\
\hline Support & & & & & & 1 & -0.02 & -0.12 & 0.14 & $-0.26^{\dagger}$ & $-0.27^{\dagger}$ \\
\hline BMI (kg/m²) & & & & & & & 1 & $0.91 * * *$ & 0.13 & $0.37 * *$ & $0.36^{* *}$ \\
\hline $\mathrm{WC}(\mathrm{cm})$ & & & & & & & & 1 & 0.04 & $0.45 * * *$ & $0.45 * * *$ \\
\hline $\operatorname{logEBV}$ & & & & & & & & & 1 & -0.03 & -0.15 \\
\hline SBP (mmHg) & & & & & & & & & & 1 & $0.73 * * *$ \\
\hline DBP (mmHg) & & & & & & & & & & & 1 \\
\hline
\end{tabular}

TR: time in residency; SES: socioeconomic status; Inferior: reported being treated as if inferior; ELO: English language orientation; Support: family support; BMI: body mass index; WC: waist circumference; EBV: Epstein-Barr virus; SBP: systolic blood pressure; DBP: diastolic blood pressure.

$\dagger p<0.10 ; * p<0.05 ; * * p<0.01 ; * * * p<0.001$.

${ }^{a} Z$-scored variable combining education and household income. 
Table 3. Multiple regression models for prediction of EBV antibody levels among male and female Latino immigrants

\begin{tabular}{|c|c|c|c|}
\hline Measure \& variables & Regression coefficient $(b \pm \mathrm{SE})$ & $B$ & Overall $r^{2}$ \\
\hline Men & & & $0.61 * *$ \\
\hline Constant & $1.78(0.11)$ & & \\
\hline Inferior & $0.19(0.05)$ & $0.81 * * *$ & \\
\hline SES & $-0.003(0.06)$ & -0.007 & \\
\hline ELO & $-0.13(0.06)$ & $-0.36^{*}$ & \\
\hline Support & $-0.07(0.05)$ & -0.21 & \\
\hline Inferior $\times$ SES & $0.27(0.07)$ & $0.74 * * *$ & \\
\hline Women & & & 0.16 \\
\hline Constant & $2.08(0.11)$ & & \\
\hline Inferior & $-0.07(0.04)$ & $-0.33^{\dagger}$ & \\
\hline SES & $-0.04(0.06)$ & -0.10 & \\
\hline ELO & $-0.01(0.05)$ & -0.03 & \\
\hline Support & $0.05(0.04)$ & 0.20 & \\
\hline Inferior $\times$ SES & $0.008(0.06)$ & 0.02 & \\
\hline
\end{tabular}

$\dagger p<0.10 ; * p<0.05 ; * * p<0.01 ; * * * p<0.001$.

strengthened only slightly $(r=-0.29, p=0.06)$. Women's higher EBV levels were marginally correlated with TR (Table 2); after adjusting for SES, this relationship became significant $(r=0.32, p=0.04)$. Higher EBV among women was unrelated to either ELO or family support, even after controlling for SES (ELO: $r=0.12, p>0.10$; Support: $r=0.14, p>0.10$ ).

Multiple regression analyses investigated interaction effects between discriminationrelated stress and SES in relation to EBV (Table 3). Among men, increases in discrimination-related stress predicted elevated EBV levels, with the interaction between stress and SES explaining $61 \%$ of the variance in men's EBV levels. Plotting the same results using ANOVA shows that men who reported experiencing no discrimination-related stress, and who were in the upper $50 \%$ of men's SES, had slightly lower EBV levels than men with lower SES (Fig. 1). In the presence of discrimination-related stress, however, the EBV levels of men with higher SES elevated noticeably more than those of men with lower SES. Lower levels of ELO similarly predicted elevated EBV among men. Among women, discrimination-related stress showed a negative trend in relation to EBV, with no significant associations detected between EBV and any of the independent variables included in the model.

\section{Stress and blood pressure}

Only one female participant and no male participants were classified as hypertensive $(\mathrm{SBP}>140 \mathrm{mmHg}$ or $\mathrm{DBP}>90 \mathrm{mmHg}$ ). An additional $25 \%$ of men and $26 \%$ of women measured as prehypertensive ( $\mathrm{SBP}=120-139 \mathrm{mmHg}$ or $\mathrm{DBP}=80-89 \mathrm{mmHg}$ ).

When partial correlations were run to examine men's SBP and DBP in relation to discrimination-related stress (controlling for age and waist circumference), no 


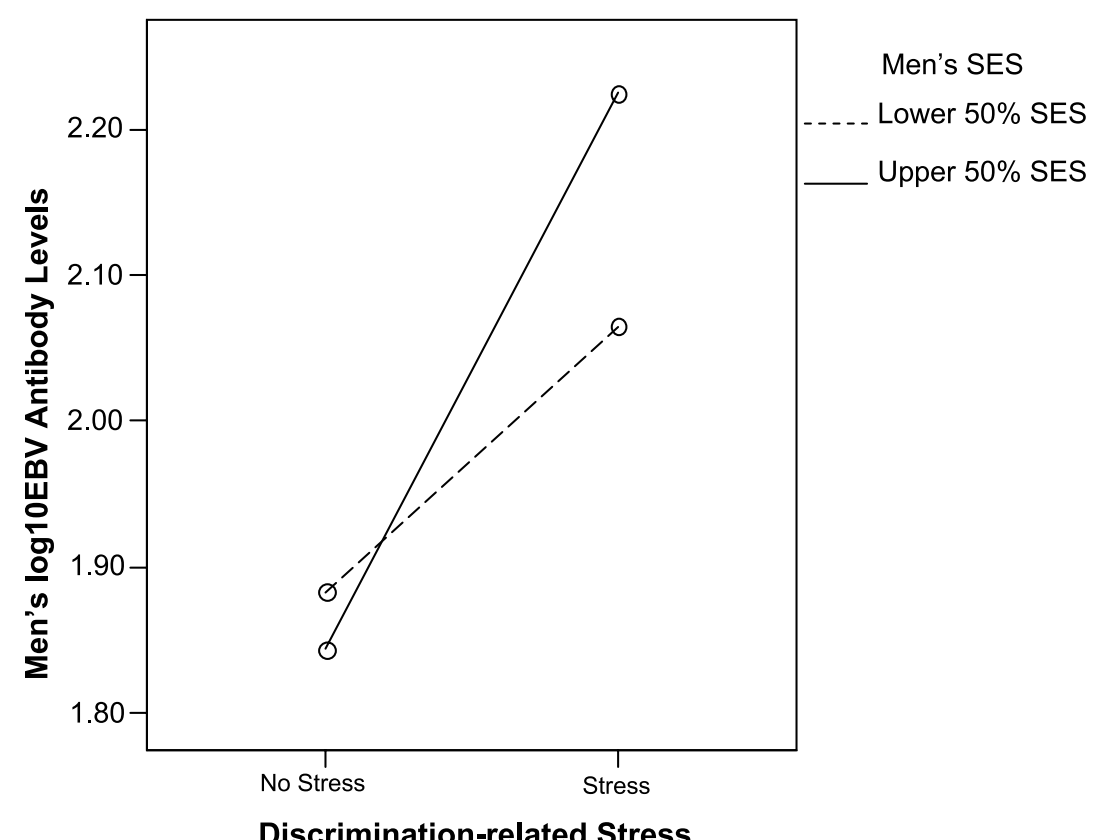

Fig. 1. Univariate analysis of variance of $\log _{10}$ EBV antibody levels, SES and discrimination-related stress for male Latino immigrants.

significant relationships were detected (Table 4). Diastolic blood pressure was unrelated to men's family support but, after controlling for SES in addition to age and waist circumference, higher DBP was significantly related to lower family support $(r=-0.41, p=0.05)$. Family support was unrelated to men's SBP, and TR, ELO and SES were unrelated to both men's SBP and DBP (Table 4).

Women's discrimination-related stress also was unrelated to both SBP and DBP (Table 4). Women's ELO approached significance with SBP and, after controlling for SES in addition to age and waist circumference, women's SBP significantly and positively associated with ELO ( $r=0.31, p=0.05$; Fig. 2). Women's DBP was significantly and positively related to TR, and showed a negative trend with family support (Table 4). After adjusting for women's SES in addition to age and waist circumference, women's DBP remained significantly correlated with TR $(r=0.33$, $p=0.04)$, though DBP no longer related to family support $(r=-0.24, p>0.10)$.

Multiple regression analyses explored potential interaction effects between discrimination-related stress and SES in relation to each of SBP and DBP. In addition, unlike findings from bivariate correlations, multiple regressions allow for the detection of the unique effect of discrimination-related stress on blood pressure after controlling for the variance accounted for by SES, ELO and family support. In regression models, increases in men's discrimination-related stress predicted elevations in men's SBP, and a significant interaction effect was observed between discrimination-related stress and SES in a model explaining $65 \%$ of the variance in men's SBP levels (Table 5). An ANOVA plot illustrates that men who reported experiencing no discrimination-related 
Table 4. Partial correlation matrix for blood pressure and sociocultural variables (adjusted for age and waist circumference) by sex

\begin{tabular}{lccccccc}
\hline Variables & SBP & DBP & TR & SES & Inferior & ELO & Support \\
\hline Men & & & & & & & \\
$\quad$ SBP (mmHg) & 1 & $0.55^{* *}$ & 0.04 & -0.15 & 0.33 & 0.001 & -0.15 \\
DBP (mmHg) & & 1 & -0.02 & 0.06 & 0.05 & 0.06 & $-0.33^{\dagger}$ \\
TR (years) & & & 1 & 0.09 & 0.13 & 0.30 & 0.29 \\
SES & & & 1 & -0.31 & $0.38^{\dagger}$ & 0.05 \\
Inferior & & & & 1 & -0.09 & 0.24 \\
ELO & & & & & 1 & 0.30 \\
Support & & & & & & 1 \\
Women & & & & & & \\
SBP (mmHg) & 1 & $0.72^{* * *}$ & 0.22 & 0.18 & -0.09 & $0.28^{\dagger}$ & -0.22 \\
DBP (mmHg) & & 1 & $0.33^{*}$ & 0.09 & -0.09 & 0.23 & $-0.24^{\dagger}$ \\
TR (years) & & & $0.35^{*}$ & -0.01 & $0.39^{* *}$ & -0.09 \\
SES & & & 1 & -0.06 & $0.37^{* *}$ & -0.13 \\
Inferior & & & & & -0.11 & 0.06 \\
ELO & & & & & 1 & $-0.31^{*}$ \\
Support & & & & & & & 1 \\
\hline
\end{tabular}

SBP: systolic blood pressure; DBP: diastolic blood pressure; TR: time in residency; SES: socioeconomic status; Inferior: reported being treated as if inferior; ELO: English language orientation; Support: family support.

$\dagger p<0.10 ; * p<0.05 ; * * p<0.01 ; * * * p<0.001$.

stress had lower SES and lower SBP levels (Fig. 3). In the presence of discriminationrelated stress, however, the SBP levels of men with lower SES were most noticeably elevated. In addition, decreases in family support predicted increases in men's SBP. The model including discrimination stress and other covariates also showed a trend toward predicting elevated DBP among men $(p=0.06$; Table 5), though only decreased family support showed a unique effect in predicting men's increased DBP. Among women, there were no detected effects on blood pressure of discrimination-related stress or of the interaction between stress and SES (Table 5).

\section{Discussion}

Results from the present study provided mixed support for hypotheses. Higher blood pressure among women (but not men) was associated with more years in the US and greater engagement with English language activities. Higher SBP and EBV antibody levels among men (but not women) were predicted by discrimination-related stress. Surprisingly, women's higher discrimination stress related to lowered EBV antibody levels. Though further research is required to confirm these results, this study illustrates that the incorporation of biological measures into an investigation of perceived discrimination and elements of acculturation may provide insights into the links among psychosocial stress and physiological effects among Latino immigrants. 


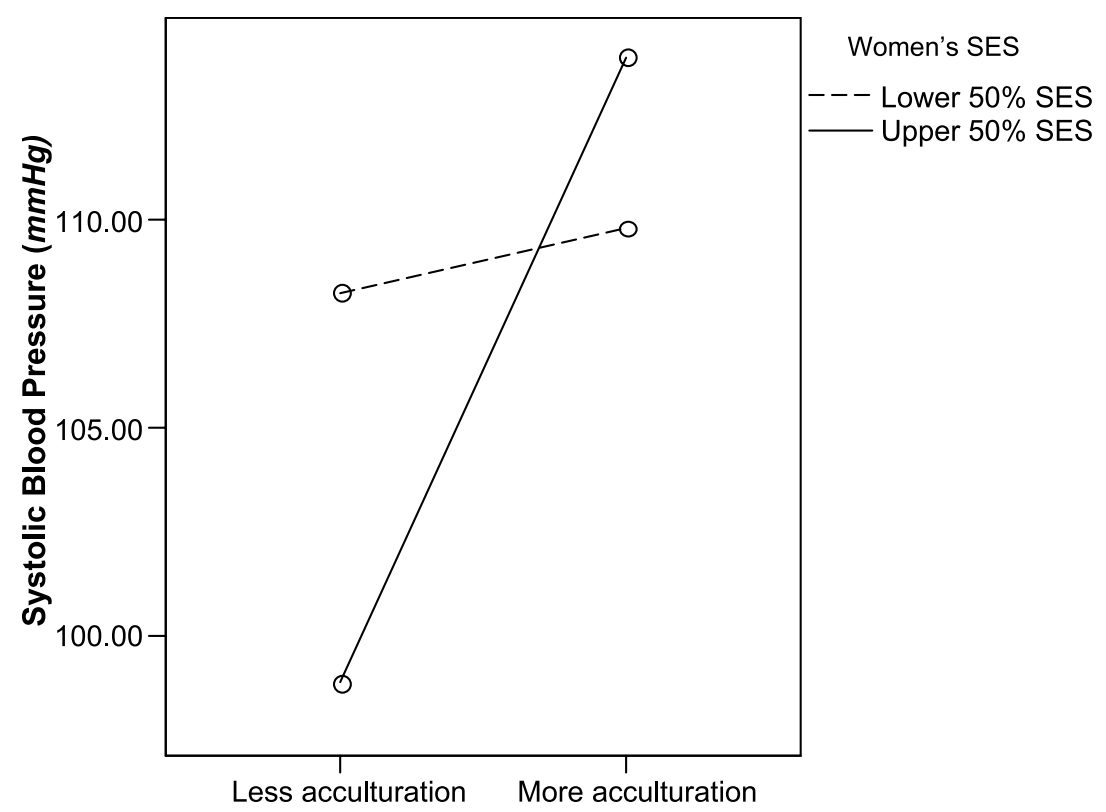

Fig. 2. Univariate analysis of variance of systolic blood pressure (SBP), acculturation and SES (adjusted for age and waist circumference) as covariates for female Latina immigrants.

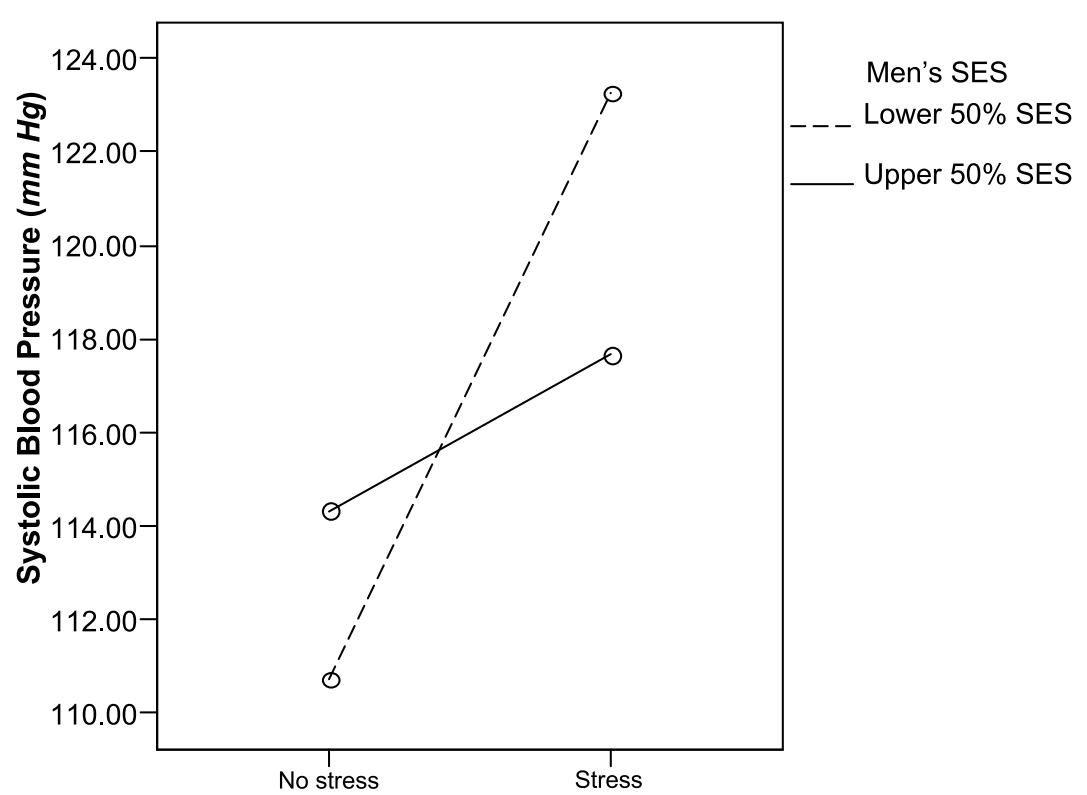

Fig. 3. Univariate analysis of variance of systolic blood pressure and SES (adjusted for age and waist circumference) for male Latino immigrants. 
Table 5. Multiple regression models for prediction of SBP and DBP among male and female Latino immigrants

\begin{tabular}{|c|c|c|c|}
\hline Measure \& variables & Regression coefficient $(b \pm \mathrm{SE})$ & $B$ & Overall $r^{2}$ \\
\hline \multicolumn{4}{|l|}{ Men } \\
\hline SBP & & & $0.65^{* *}$ \\
\hline Constant & $92.68(13.38)$ & & \\
\hline Age & $0.24(0.20)$ & 0.23 & \\
\hline WC & $0.13(0.13)$ & 0.16 & \\
\hline Inferior & $5.56(1.78)$ & $0.66^{* *}$ & \\
\hline SES & $-2.58(2.64)$ & -0.17 & \\
\hline Acculturation & $1.24(2.14)$ & 0.10 & \\
\hline Support & $-3.47(1.82)$ & $-0.31^{\dagger}$ & \\
\hline Inferior $\times$ SES & $7.90(3.36)$ & $0.59^{*}$ & \\
\hline DBP & & & $0.49^{\dagger}$ \\
\hline Constant & $55.39(12.26)$ & & \\
\hline Age & $0.30(0.18)$ & 0.38 & \\
\hline WC & $0.09(0.12)$ & 0.15 & \\
\hline Inferior & $2.48(1.63)$ & 0.38 & \\
\hline SES & $0.40(2.36)$ & 0.04 & \\
\hline Acculturation & $1.14(1.93)$ & 0.11 & \\
\hline Support & $-3.39(1.61)$ & $-0.39 *$ & \\
\hline Inferior $\times$ SES & $3.97(3.04)$ & 0.39 & \\
\hline \multicolumn{4}{|l|}{ Women } \\
\hline SBP & & & $0.46^{* *}$ \\
\hline Constant & $61.63(13.02)$ & & \\
\hline Age & $0.60(0.21)$ & $0.41 * *$ & \\
\hline WC & $0.34(0.15)$ & $0.34^{*}$ & \\
\hline Inferior & $-0.07(1.34)$ & -0.01 & \\
\hline SES & $0.27(2.53)$ & 0.02 & \\
\hline ELO & $3.96(2.15)$ & $0.27^{\dagger}$ & \\
\hline Support & $-0.95(1.70)$ & -0.08 & \\
\hline Inferior $\times$ SES & $0.30(2.17)$ & 0.02 & \\
\hline DBP & & & $0.33^{*}$ \\
\hline Constant & $48.39(8.92)$ & & \\
\hline Age & $0.15(0.13)$ & 0.18 & \\
\hline WC & $0.24(0.10)$ & $0.38 *$ & \\
\hline Inferior & $0.17(0.91)$ & 0.03 & \\
\hline SES & $-0.47(1.72)$ & -0.04 & \\
\hline ELO & $1.62(1.43)$ & 0.18 & \\
\hline Support & $-1.22(1.16)$ & -0.16 & \\
\hline Inferior $\times$ SES & $0.86(1.48)$ & 0.09 & \\
\hline
\end{tabular}

$\dagger p \leq 0.10 ; * p<0.05 ; * * p<0.01$.

Prevalence of psychosocial stress among Latino immigrant farm workers

Rates of discrimination reported in this study $-40 \%$ of all participants reported they felt stressed by being treated as if inferior - are higher than those reported in 
most US Latino samples (at 18 to 30\%; Stuber et al., 2003; Pérez et al., 2008), and comparable to or lower than those recorded among samples composed exclusively of Latino farm workers (at 38 to 50\%; Alderete, et al., 1999; Farquhar, et al., 2008).

This study also documented social and economic conditions that favour stress among this population. The median annual household income of US\$15,000 reported by study participants is less than a third of that for Oregon households in general (US Census Bureau, 2008b). Evidence shows that low household incomes and concentrated poverty are significantly related to lowered social support, increased depression and other stressors (Schulz et al., 2006; Williams \& Latkin, 2007). Forty per cent of heads of households reported living in food-insecure households without hunger, and an additional 14\% reported not having sufficient food during the past year; hunger rates reported by study participants are two times higher than those among US Latinos (5\%) or blacks (6\%) (US Department of Agriculture, 2005). Though nutritional status can influence physical health measures and immune function (e.g. Vozoris \& Tarasuk, 2003; Tanumihardjo et al., 2007), no significant relationships were observed between food insecurity and each of EBV antibody levels, SBP or DBP among men or women (results not shown here). Finally, the rate of uninsured among participants at $72 \%$ was significantly higher than that for Latinos nationwide $(43 \%$; Centers for Disease Control and Prevention, 2007).

\section{Perceiving stress: discrimination, acculturation and physiological change}

Among men, perceived discrimination predicted increases in EBV antibody levels and in SBP, a similar pattern to that documented in prior studies of discrimination and blood pressure (Krieger et al., 1999; Ryan et al., 2006; Sweet et al., 2007). Also similar to other studies was the finding that men's DBP is not strongly related to discrimination-related stress (Krieger \& Sidney, 1996; Ryan et al., 2006).

Socioeconomic status appears to influence men's discrimination-related stress - a finding in keeping with previous research among Latinos (Cardarelli et al., 2007; Williams, 2008) - though its effects were different for EBV antibody levels and SBP. When experiencing stress from discrimination, the most elevated EBV antibody levels were seen among men with higher SES (Fig. 1). The highest SBP levels, however, were seen among men with lower SES (Fig. 3). This finding may reflect differences in men's exposure to discrimination in the workplace and occupational stress (Finch et al., 2001; Din-Dzietham et al., 2004), particularly related to lack of control and predictability, which are recognized predictors of high stress and poor health outcomes (Pearlin et al., 1981; Williams, 2008). Though this study's design and limited sample only allow for tentative interpretations, differences in the effects of men's SES on physiological measures could reflect men's divergent experiences of psychosocial stress which, in turn, could contribute to dissimilar physiological stress responses. Evidence from neuroscience indicates that not all stressors produce the exact same stress response (e.g. Schommer et al., 2003) and that different types of stressors may have their own neurochemical 'signatures' (Pacák \& Palkovits, 2001); for instance, passive coping has been linked to cardiovascular activation (Sherwood et al., 1990; Tomaka et al., 1993) - a contributor to increased SBP over time (Cacioppo et al., 2002; Hawkley et al., 2003) - and certain types of depression have been shown to 
suppress immune function (Sabban \& Kvetnansky, 2001; Tafet \& Bernardini, 2003). These divergent results also might be explained by men's expectations related to socioeconomic status thus raising the question: are men with higher SES who perceive of higher SES as protective against discrimination more vulnerable to the effects of stress when they experience prejudice?

In contrast to results for men, women's discrimination-related stress was unrelated to both blood pressure measures, a finding in keeping with that documented in the SWAN study (Brown et al., 2006). A potential explanation for this result may reside in the role of social support as a buffer against otherwise negative influences of psychosocial stress on women's blood pressure, a finding documented elsewhere (e.g. Dressler \& Bindon, 2000). In fact, recent research suggests that stress among women, rather than spurring a 'fight or flight' reaction, may instead catalyse women to seek social affiliation and to 'tend and befriend' (Taylor et al., 2000; but see Geary \& Flinn, 2002). A trend finding provides preliminary support for an association between discrimination-related stress and family support: the greater the stress women reported feeling because of negative things said to them, the more they agreed with the statement, 'when there are problems, you can count on family' $(r=0.26 ; p=0.07)$. Other plausible alternatives for these apparent gender differences are that women have different outlets for stress responses than men, such as depression or changes in eating behaviour (Flores et al., 2008), or that women's biology may moderate stress responses differently than men's (Panter-Brick et al., 2008).

Another contrasting finding for women in comparison with men related to EBV antibody levels: for women, stress due to discrimination showed a trend toward predicting lower EBV antibody levels. Though this nearly contradictory result for women and men is surprising, it is not unprecedented. Researchers involved in a follow-up to the important Whitehall studies found opposite associations between SES gradients and glucocorticoid levels among male and female members of the British civil service (Steptoe et al., 2003).

Gender differences also were identified in analyses of acculturation variables in relation to biological measures. Among women, partial correlations revealed that greater English language orientation was associated with higher SBP, and more years in the US related to higher DBP. In multivariate regression models, men's English language engagement was unrelated to men's blood pressure, though was strongly related to EBV antibody levels, with men's lower English language orientation predicting men's elevated EBV antibody levels.

English language engagement has been shown to be both a risk and protective factor for immigrant stress exposure (Finch et al., 2000; Pérez et al., 2008). Numerous studies have demonstrated that immigrant farm workers with little or no English proficiency may experience limited employment opportunities with available jobs often characterized by high (physical) demands, potentially hazardous conditions, little autonomy and low pay (e.g. McCauley, 2005; Farquhar et al., 2008). It is unsurprising that in a study of farm workers, the lower men's English language engagement, the greater their potential exposure to occupational stressors, and the higher their chronic psychosocial stress as indicated through EBV antibody levels. This study, however, also provided evidence of the protective nature of limited English language engagement. 
Pérez and colleagues (2008) propose that non-English speaking immigrants may be protected from discrimination-related stress through linguistic isolation while Englishspeaking participants may understand when someone discriminates against them. Their observations were based on data from their nationwide study of Latinos, in which English-proficient participants reported twice the rate of everyday discrimination compared with Spanish-speaking participants in the sample. The current study's results, if confirmed with a larger sample, imply that a concern for gender might reveal differences between women and men in the relationships between discrimination-related stress and language proficiency. Equally important may be insights into the social and occupational contexts within which women and men are exposed to psychosocial stressors, including that related to unfair treatment. Relatedly, study data also raise questions of whether there may be gender differences in the relationships between acculturation variables and family support, with increased English language engagement significantly relating to more years in residency and lowered family support for women but not for men (Table 3). There was tentative evidence for one point of commonality between women and men: among both, lowered family support was shown to be associated with elevated SBP and DBP (some findings were trends; Tables 2 and 5).

In addition to a consideration of differing impacts by gender, future research on discrimination and health would benefit from the consideration of potential confounds such as ethnic identity formation (Eccleston \& Major, 2006; Rumbaut, 2008), and strategies related to coping and presentation of self to mitigate the health effects of exposure to discrimination (Brondolo et al., 2009a). As Ryan and colleagues (2006) observed, elevated SBP levels were detected among individuals who reported high discrimination stress as well as among those who coped with discriminatory experience through under-reporting its effects (Hodson \& Esses, 2002; Krieger et al., 2008), thus creating a U-shaped curve. In the present study, it is unknown whether men and women differed in their willingness to acknowledge experiences of discrimination, or whether gender differences in coping and presentation of self may have had physiological consequences; however, no U-shaped relationship was detected between discrimination stress and SBP for either women or men.

\section{Do perceived discrimination and acculturative strains diminish immigrant health?}

In recent years, researchers have begun to explore the possibility that discrimination experienced as part of the process of 'becoming American' (Portes \& Cobas, 1980; Viruell-Fuentes, 2007) is linked to negative health effects over time among immigrants, and that this negative health trajectory can extend to later generations (Gee et al., 2006; Pérez et al., 2008). Many scholars point to discrimination as a learned and context-dependent process through which recent immigrants embody their ascribed status as US minorities (Krieger et al., 2005), a status that for Mexican-origin immigrants, in particular, may be stigmatized regardless of an individual's legal status (Finch et al., 2000; Stephen, 2007).

Observed differences between men and women in the relationships among discrimination-related stress and biological measures raise the question of whether perceived discrimination might have mixed effects on immigrant health. Is it possible 
that discrimination-related stress may diminish men's health but, when experienced by women, catalyse social support processes that are ultimately protective of women's health? Results from the present study, if confirmed with a larger sample, suggest that different associations may exist among biological markers of stress and English language orientation for women and men, with distinct implications for women and men's health. In addition, if future studies reinforce the present findings, research into the effects of psychosocial stress on men's health might take into account gradients in SES.

\section{Does psychosocial stress contribute to chronic disease progression?}

This study's findings that perceived discrimination predicted elevated SBP among male participants, and that greater English language engagement relates to increased SBP among female participants may, if replicated in a larger sample, have clinical implications given that elevated SBP is an established risk factor for cardiovascular disease (CVD; Kannel et al., 1996; Lenfant et al., 2003). The links between EBV and CVD are less known, though recent evidence suggests that immunologically mediated processes contributing to inflammation (a recognized component of CVD) may be involved in disease initiation and progression (Ross, 1999; Libby et al., 2002). Whether discrimination and other stressors experienced as a part of immigrant acculturation to the US cause elevated blood pressure and EBV antibodies is a topic for future research that could benefit from multi-site longitudinal methods (e.g. measurements taken in countries of origin before emigration and after immigration to the US).

\section{Limitations}

This study's small sample size may contribute to the mixed and, at times, contradictory findings described above. In addition, the use of only a few items from validated instruments may have reduced the variance of responses and influenced results. Due to the reliance on a non-probability design, this study's findings regarding prevalence of discrimination, or associations between discrimination and health, may have limited relevance for Latino immigrants who are not residents of the partnering community-based organization in this study, or who live in other regions of Oregon or the United States.

The sampling frame raises particular concerns related to selection biases. The sample was composed of Latino immigrant farm workers in Oregon who were probably higher on the SES gradient, and had more social support than most farm workers (K. Ross, personal communication), particularly when compared with workers who live in poor conditions in work camps (Stephen, 2007; Farquhar et al., 2008). A more random, representative sample of Latino immigrant farm workers may well document higher levels of psychosocial stress and greater associated health risks (Ross, 2007).

This study's measurement of the constructs of discrimination, acculturation and family support posed limitations. The use of a binary question to determine whether participants have ever experienced unfair treatment raises concern as to whether this measure is a valid instrument of discrimination-related stress, though it is promising that a single item would yield a prevalence rate comparable to those of studies that rely 
on more thorough assessment. This result may serve as evidence of Williams and colleagues' (2003) observation that the most useful way to measure discrimination may be to ask about perceptions of unfair treatment. The current measure of perceived discrimination clearly needs to be expanded to address an array of discriminatory experiences and coping strategies, including at the individual and neighbourhood levels. In Oregon, the social stigmatization of Mexican origin immigrants (Stephen, 2007) may dovetail with interpersonal and neighbourhood-based experiences of discrimination in ways that impact immigrant health (Finch et al., 2000). In relation to acculturation, future incorporation of measures of ethnic identity formation, language use in a range of contexts (e.g. work, school, home), and that gauge cultural orientation, including of biculturalism, might provide additional insights. Finally, the reliance on a single item focused exclusively on family support substantially limited exploration of the potential mediating effect of social support on women's and men's stress and health. Future research might investigate if gender dissimilarities in the physiological effects of discrimination and acculturation among Latino immigrants may be related to larger differences in women and men's biosocial worlds.

\section{Conclusion}

This study is a step toward filling the gap in what is currently known about the influence of perceived discrimination and related stress on health. Insights into the effects of discrimination stress, elements of acculturation and socioeconomic status on biological measures can further understanding of the social determinants that may contribute to chronic disease progression among Latino immigrants. If these connections are confirmed, it is possible that chronic disease prevention and public health policies that target immigrants may benefit through a focus on protecting against the effects of discrimination and other stressors associated with adjustment to life in the United States.

\section{Acknowledgments}

The authors thank the study assessors and participants, Felicia Madimenos for biomarker training assistance, and Lynn Stephen and Frances White for discussions of the project. They appreciate the support of the National Institutes on Drug Abuse, National Institutes of Health (R01 DA017937 and R01 DA01965), as well as the Oregon Social Learning Center Scientists' Council, Northwestern University, and the University of Oregon.

\section{References}

Affleck, G., Urrows, S., Tennen, H., Higgins, P., Pav, D. \& Aloisi, R. (1997) A dual pathway model of daily stressors effects on rheumatoid arthritis. Annals of Behavioral Medicine 19, 161-170.

Alderete, E., Vega, W. A., Kolody, B. \& Aguilar-Gaxiola, S. (1999) Depressive symptomatology: Prevalence and psychosocial risk factors among Mexican American migrant farm workers in California. Journal of Community Psychology 27(4), 457-471. 
Berry, J. W. (1998) Acculturation and health: Theory and research. In Kazarian, S. S. \& Evans, D. R. (eds) Cultural Clinical Psychology: Theory, Research, and Practice. Oxford University Press, New York, pp. 39-57.

Black, H. R. (1999) The paradigm has shifted, to systolic blood pressure. Hypertension 34(3), 386-387.

Boeckner, L. S., Pullen, C. H., Walker, S. N. \& Hageman, P. A. (2006) Differences in eating and activity behaviors, health history, and biomarkers among normal-weight, overweight, and-obese rural Midwestern Hispanic women. Journal of the American Diatetic Association 106(11), 1870-1874.

Bongard, S., Pogge, S. F., Arslaner, H., Rohrmann, S. \& Hodapp, V. (2002) Acculturation and cardiovascular reactivity of second-generation Turkish migrants in Germany. Journal of Psychosomatic Research 53, 795-803.

Brondolo, E., Brady, N., Pencille, M., Betty, D. \& Contrada, R. J. (2009a) Coping with racism: A selective review of the literature and a theoretical and methodological critique. Journal of Behavioral Medicine 32(1), 64-88.

Brondolo, E., Gallo, L. C. \& Myers, H. F. (2009b) Race, racism, and health: Disparities, mechanisms, and interventions. Journal of Behavioral Medicine 32, 1-8.

Brondolo, E., Libby, D. J., Denton, E., Thompson, S., Beatty, D. L., Schwartz, J. et al. (2008) Racism and ambulatory blood pressure in a community sample. Psychosomatic Medicine 70, 49-56.

Brown, C., Matthews, K. A., Bromberger, J. T. \& Chang, Y. (2006) The relation between perceived unfair treatment and blood pressure in a racially/ethnically diverse sample of women. American Journal of Epidemiology 164, 257-262.

Cabassa, L. J. (2003) Measuring acculturation: Where we are and where we need to go. Hispanic Journal of Behavioral Sciences 25, 127-146.

Cacioppo, J. T., Hawkley, L. C., Crawford, L. E., Ernst, J. M., Burleson, M. H., Kowalewski, R. B. et al. (2002) Loneliness and health: Potential mechanisms. Psychosomatic Medicine 64, 407-417.

Cardarelli, R., Cardarelli, K. M. \& Chiapa, A. L. (2007) The modifying effects of education and income on Hispanics reporting perceived discrimination. Hispanic Journal of Behavioral Sciences 29(3), 401-407.

Carter-Pokras, O. \& Bethune, L. (2009) Defining and measuring acculturation: A systematic review of public health studies with Hispanic populations in the United States. A commentary on Thomson and Hoffman-Goetz. Social Science \& Medicine 69, 992-995.

Centers for Disease Control and Prevention (CDC) (2007) Behavioral risk factor surveillance system prevalence data. URL: http://apps.nccd.cdc.gov/BRFSS/race.asp?cat=HC\&yr=2007\& qkey $=880 \&$ state $=$ UB (accessed 21st November 2008).

Cervantes, R. C., Padilla, A. M. \& Salgado de Snyder, N. (1990) Reliability and validity of the Hispanic Stress Inventory. Hispanic Journal of Behavioral Sciences 12(1), 76-82.

Contrada, R. J., Ashmore, R. D., Gary, M. L., Coups, E., Egeth, J. D., Sewell, A. et al. (2001) Measures of ethnicity-related stress: Psychometric properties, ethnic group differences, and associations with well-being. Journal of Applied Social Psychology 31, 1775-1820.

Cuellar, I., Arnold, B. \& Maldonado, R. (1995) Acculturation Rating Scale for Mexican Americans-II: A revision of the original ARSMA scale. Hispanic Journal of Behavioral Sciences 17(3), 275-304.

Din-Dzietham, R., Nembhard, W. N., Collins, R. \& Davis, S. K. (2004) Perceived stress following race-based discrimination at work is associated with hypertension in African-Americans. The metro Atlanta heart disease study, 1999-2001. Social Science \& Medicine 58, 449-461. 
Dominguez, T. P., Strong, E. F., Krieger, N., Gillman, M. W. \& Rich-Edwards, J. W. (2009) Differences in the self-reported racism experiences of US-born and foreign-born Black pregnant women. Social Science \& Medicine DOI:10.1016/j.socscimed.2009.03.022.

Dressler, W. W. (1990) Lifestyle, stress, and blood pressure in a Southern black community. Psychosomatic Medicine 52, 182-198.

Dressler, W. W. \& Bindon, J. R. (2000) The health consequences of cultural consonance: Cultural dimensions of lifestyle, social support, and arterial blood pressure in an African American community. American Anthropologist 102(2), 244-260.

Dressler, W. W., Oths, K. S. \& Gravlee, C. C. (2005) Race and ethnicity in public health research: Models to explain health disparities. Annual Review of Anthropology 34, 231-252.

Eccleston, C. P. \& Major, B. N. (2006) Attributions to discrimination and self-esteem: The role of group identification and appraisals. Group Processes \& Intergroup Relations 9(2), $147-162$.

Escobar, J. I. \& Vega, W. A. (2000) Mental health and immigration's AAAs: Where are we and where do we go from here? Journal of Nervous \& Mental Disease 188(11), 736-740.

Farquhar, S., Samples, J., Ventura, S., Davis, S., Abernathy, M., McCauley, L. et al. (2008) Promoting the occupational health of indigenous farm workers. Journal of Immigrant \& Minority Health 10(3), 269-280.

Finch, B. K., Boardman, J. D., Kolody, B. \& Vega, W. A. (2000) Contextual effects of acculturation on perinatal substance exposure among immigrant and native-born Latinas. Social Science Quarterly 81, 421-438.

Finch, B. K., Hummer, R. A., Kolody, B. \& Vega, W. A. (2001) The role of discrimination and acculturative stress in the physical health of Mexican-origin adults. Hispanic Journal of Behavioral Sciences 23, 399-429.

Finch, B. K. \& Vega, W. A. (2003) Acculturation stress, social support, and self-rated health among Latinos in California. Journal of Immigrant Health 5(3), 109-117.

Flores, E., Tschann, J. M., Dimas, J. M., Bachen, E. A., Pasch, L. A. \& de Groat, C. L. (2008) Perceived discrimination, perceived stress, and mental and physical health among Mexicanorigin adults. Hispanic Journal of Behavioral Sciences 30(4), 401-424.

Geary, D. \& Flinn, M. (2002) Sex differences in behavioral and hormonal response to social threat: Commentary on Taylor et al. Psychological Reviews 109, 745-750.

Gee, G. C., Ryan, A., Laflamme, D. J. \& Holt, J. (2006) Self-reported discrimination and mental health status among African descendants, Mexican Americans, and other Latinos in the New Hampshire REACH 2010 Initiative: The added dimension of immigration. American Journal of Public Health 96(10), 1821-1828.

Glaser, R., Kiecolt-Glaser, J. K., Speicher, C. E. \& Holliday, J. E. (1985) Stress, loneliness, and changes in herpesvirus latency. Journal of Behavioral Medicine 8, 249-260.

Glaser, R., Pearson, G. R., Jones, J. F., Hillhouse, J., Kennedy, S., Mao, H. \& Kiecolt-Glaser, J. K. (1991) Stress-induced activation of Epstein-Barr virus. Brain, Behavior, and Immunity 5, 219-232.

Gravlee, C. C., Dressler, W. W. \& Bernard, H. R. (2005) Skin color, social classification, and blood pressure in southeastern Puerto Rico. American Journal of Public Health 95(12), 2191-2197.

Gustafsson, P. E., Gustafsson, P. A. \& Nelson, N. (2006) Cortisol levels and psychosocial factors in preadolescent children. Stress and Health: Journal of the International Society for the Investigation of Stress 22(1), 3-9.

Hanna, J. M. (1998) Migration and acculturation among Samoans: Some sources of stress and support. Social Science \& Medicine 46, 1325-1336. 
Harachi, T. W., Catalano, R. F. \& Hawkins, J. D. (1997) Effective recruitment for parenting programs within ethnic minority communities. Child and Adolescent Social Work Journal 14(1), 23-39.

Harrell, J. P., Hall, S. \& Taliaferro, J. (2003) Physiological responses to racism and discrimination: An assessment of the evidence. American Journal of Public Health 93, 243-248.

Harrison, G. G., Stormer, A., Herman, D. R. \& Winham, D. M. (2003) Development of a Spanish-language version of the U.S. household food security survey module. Journal of Nutrition 133, 1192-1197.

Hawkley, L. C., Burleson, M. H., Berntson, G. G. \& Cacioppo, J. T. (2003) Loneliness in everyday life: Cardiovascular activity, psychosocial context, and health behaviors. Journal of Personality \& Social Psychology 85, 105-120.

Henle, W. \& Henle, G. (1982) Epstein-Barr virus and infectious mononucleosis. In Glaser, R. \& Gottleib-Stematsky, T. (eds) Human Herpesvirus Infections: Clinical Aspects. Marcel Dekker, New York, pp. 151-162.

Ho, S. Y., Lam, T. H. \& Janus, E. D. (2003) Waist to stature ratio is more strongly associated with cardiovascular risk factors than other simple anthropometric indices. Annals of Epidemiology 13, 683-691.

Hodson, G. \& Esses, V. M. (2002) Distancing oneself from negative attributes and the personal/group discrimination discrepancy. Journal of Experimental Social Psychology 38, 500-507.

Institute of Medicine (2002) Unequal Treatment: Confronting Racial and Ethnic Disparities in Health Care. National Academy Press, Washington, DC.

James, K., Lovato, C. \& Khoo, G. (1994) Social identity correlates of minority workers' health. Academy of Management Journal 37(2), 383-396.

Jones, J. F. \& Straus, S. E. (1987) Chronic Epstein-Barr virus infection. Annual Review of Medicine 38, 195-209.

Jurkowski, J. M., \& Johnson, T. P. (2005) Acculturation and cardiovascular disease screening practices among Mexican Americans living in Chicago. Ethnicity \& Disease 15(3), 411-417.

Kannel, W. B., Wolf, P. A., Verter, J. \& McNamara, P. M. (1996) Epidemiologic assessment of the role of blood pressure in stroke: The Framingham Study, 1970. Journal of the American Medical Association 276(15), 1269-1278.

Kaplan, N. M. (2005) Kaplan's Clinical Hypertension (9th edition). Lippincott Williams \& Wilkins, Philadelphia.

Kessler, R. C., Mickelson, K. D. \& Williams, D. R. (1999) The prevalence, distribution, and mental health correlates of perceived discrimination in the United States. Journal of Health and Social Behavior 40(3), 208-230.

Kiecolt-Glaser, J. K., Glaser, R., Shuttleworth, E. C., Dyer, C. S., Ogrocki, P. \& Speicher, C. E. (1987) Chronic stress and immunity in family caregivers of Alzheimer's disease victims. Psychosomatic Medicine 49, 523-535.

Kiecolt-Glaser, J. K., Malarkey, W. B., Cacioppo, J. T. \& Glaser, R. (1994) Stressful personal relationships: Immune and endocrine function. In Glaser, R. \& Kiecolt-Glaser, J. K. (eds) Handbook of Human Stress and Immunity. Academic Press, San Diego, CA, pp. 321-329.

Kiecolt-Glaser, J. K., Malarkey, W. B., Chee, M. A., Newton, T., Cacioppo, J. T., Mao, H. Y. \& Glaser, R. (1993). Negative behavior during marital conflict is associated with immunological down-regulation. Psychosomatic Medicine 55, 395-409.

Kiecolt-Glaser, J. K., Marucha, P. T., Malarkey, W. B., Mercado, A. M. \& Glaser, R. (1995) Slowing of wound healing by psychological stress. Lancet 346, 1194-1196. 
Kiecolt-Glaser, J. K., Ricker, D., George, J., Messick, G., Speicher, C. E., Garner, W. \& Glaser, R. (1984) Urinary cortisol levels, cellular immunocompetency, and loneliness in psychiatric inpatients. Psychosomatic Medicine 46, 15-23.

Krieger, N., Chen, J. T., Waterman, P. D., Hartman, C., Stoddard, A. M., Quinn, M. M. et al. (2008) The inverse hazard law: Blood pressure, sexual harassment, racial discrimination, workplace abuse and occupational exposures in US low-income black, white and Latino workers. Social Science \& Medicine 67, 1970-1981.

Krieger, N. \& Sidney, S. (1996) Racial discrimination and blood pressure: The CARDIA study of young black and white adults. American Journal of Public Health 86, 1370-1378.

Krieger, N., Sidney, S. \& Coakley, E. (1999) Racial discrimination and skin color in the CARDIA study: Implications for public health research. American Journal of Public Health 88, 1308-1313.

Krieger, N., Smith, K., Naishadham, D., Hartman, C. \& Barbeau, E. M. (2005) Experiences of discrimination: Validity and reliability of a self-report measure for population health research on racism and health. Social Science \& Medicine 61, 1576-1596.

Kunz-Ebrecht, S., Kirschbaum, C., Marmot, M. \& Steptoe, A. (2004) Differences in cortisol awakening response on work days and weekends in women and men from the Whitehall II cohort. Psychoneuroendocrinology 29, 516-528.

Landrine, H., Klonoff, E. A., Corral, I., Fernandez, S. \& Roesch, S. (2006) Conceptualizing and measuring ethnic discrimination in health research. Journal of Behavioral Medicine 29, 79-94.

Lara, M., Gamboa, C., Kahramanian, M. I., Morales, L. S. \& Hayes Bautista, D. E. (2005) Acculturation and Latino health in the United Status: A review of the literature and its sociopolitical context. Annual Review of Public Health 26, 367-397.

Lenfant, C., Chobanian, A. V., Jones, D. W. \& Roccella, E. J. (2003) Seventh report of the Joint National Committee on Prevention, Detection, Evaluation, and Treatment of High Blood Pressure (JNC 7): Resetting the hypertension sails. Hypertension 42, 1206-1252.

Libby, P., Ridker, P. M. \& Maseri, A. (2002) Inflammation and atherosclerosis. Circulation 105, $1135-1143$.

Lohman, T. G., Roche, A. F. \& Martorell, R. (eds) (1988) Anthropometric Standardization Reference Manual. Human Kinetics Books, Champaign.

Lupien, S., King, S., Meaney, M. \& McEwen, B. (2000) Child's stress hormone levels correlate with mother's socioeconomic status and depressive state. Biological Psychiatry 48, 976-980.

McCauley, L. A. (2005) Immigrant workers in the United States: Recent trends, vulnerable populations, and challenges for occupational health. American Association of Occupational Health Nurses Journal 53, 313-319.

McDade, T. W. (2001) Lifestyle incongruity, social integration, and immune function in Samoan adolescents. Social Science \& Medicine 53, 1351-1362.

McDade, T. W. (2007) Measuring immune function: Markers of cell-mediated immunity and inflammation in dried blood spots. In Ice, G. H. \& James, G. D. (eds) Measuring Stress in Humans: A Practical Guide for the Field. Cambridge University Press, Cambridge.

McDade, T. W., Stallings, J. F., Angold, A., Costello, E. J., Burleson, M., Cacioppo, J. T. et al. (2000a) Epstein-Barr Virus antibodies in whole blood spots: A minimally invasive method for assessing an aspect of cell-mediated immunity. Psychosomatic Medicine 62, 560-567.

McDade, T. W., Stallings, J. F. \& Worthman, C. M. (2000b) Culture change and stress in Western Samoan youth: Methodological issues in the cross-cultural study of stress and immune function. American Journal of Human Biology 12, 792-802. 
McDade, T. W., Williams, S. \& Snodgrass, J. J. (2007) What a drop can do: Dried blood spots as a minimally invasive method for integrating biomarkers into population-based research. Demography 44(4), 899-925.

McDade, T. W. \& Worthman, C. M. (2004) Socialization ambiguity in Samoan adolescents: a model for human development and stress in the context of culture change. Journal of Research on Adolescence 14, 49-72.

Mainous, A. G. III, Majeed, A., Koopman, R. J., Baker, R., Everett, C. J., Tilley, B. C. \& Diaz, V. A. (2006) Acculturation and diabetes among Hispanics: Evidence from the 1999-2002 National Health and Nutrition Examination Survey. Public Health Reports 121(1), 60-66.

Marín, G. \& Marín, B. V. (1991) Research with Hispanic Populations. Sage, Newbury Park, CA.

Marmot, M. (2004) The Status Syndrome: How Social Standing Affects our Health and Longevity. Henry Holt \& Co., New York.

Martinez, C. R. Jr (2006) Effects of differential family acculturation on Latino adolescent substance use. Family Relations 55(3), 306-317.

Martinez, C. R. Jr, McClure, H. H. \& Eddy, J. M. (2008) Language brokering contexts and behavioral and emotional adjustment among Latino parents and adolescents. Journal of Early Adolescence 29(1), 71-98.

Marucha, P. T., Kiecolt-Glaser, J. K. \& Favagchi, M. (1998) Mucosal wound healing is impaired by examination stress. Psychosomatic Medicine 60, 362-365.

Mason, P. (2004) Annual income, hourly wages, and identity among Mexican-Americans and other Latinos. Industrial Relations 43(4), 817-834.

Matheson, K., Jorden, S. \& Anisman, H. (2008) Relations between trauma experiences and psychological, physical and neuroendocrine functioning among Somali refugees: Mediating role of coping with acculturation stressors. Journal of Immigrant and Minority Health 10 291-304.

National Center for Health Statistics (NCHS) (2006) National Health Interview Survey. Centers for Disease Control and Prevention. URL: http://www.cdc.gov/nchs/about/major/nhis/ quest_data_related_1997_forward.htm

National Institutes of Health (2000) The Practical Guide: Identification, Evaluation, and Treatment of Overweight and Obesity in Adults. National Institutes of Health, Bethesda, MD.

Pacák, K. \& Palkovits, M. (2001) Stressor specificity of central neuroendocrine responses: Implications for stress-related disorders. Endocrine Reviews 22(4), 502-548.

Panter-Brick, C., Eggerman, M., Mojadidi, A. \& McDade, T. W. (2008) Social stressors, mental health, and physiological stress in an urban elite of young Afghans in Kabul. American Journal of Human Biology 20, 627-641.

Pantin, H., Schwartz, S. J., Coatsworth, J. D., Sullivan, S., Briones, E. \& Szapocznik, J. (2007) Familias Unidas: A systemic, parent-centered approach to preventing problem behavior in Hispanic adolescents. In Tolan, P., Szapocznik, J. \& Sambrano, S. (eds) Preventing Youth Substance Abuse: Science-Based Programs for Children and Adolescents. American Psychological Association, Washington, DC, pp. 211-238.

Paradies, Y. C. (2006) Defining, conceptualizing and characterizing racism in health research. Critical Public Health 16(2), 143-157.

Pearlin, L. I., Lieberman, M. A., Menaghan, E. G. \& Mullan, J. T. (1981) The stress process. Journal of Health and Social Behavior 22, 337-353.

Pérez, D. J., Fortuna, L. \& Alegría, M. (2008) Prevalence and correlates of everyday discrimination among U.S. Latinos. Journal of Community Psychology 36(4), 421-433.

Pew Hispanic Center (2007) 2007 National Survey of Latinos: As Illegal Immigration Issue Heats Up, Hispanics Feel a Chill. Pew Hispanic Center, Washington, DC.

Portes, A. \& Cobas, J. A. (1980) Assimilation or consciousness: Perceptions of U.S. society among recent Latin American immigrants to the United States. Social Forces 59(1), 200-224. 
Portes, A. \& Rumbaut, R. G. (2001) Legacies: The Story of the Immigrant Second Generation. University of California Press, Berkeley.

Ross, R. (1999) Atherosclerosis: An inflammatory disease. New England Journal of Medicine 340, 115-126.

Rumbaut, R. G. (2008) Reaping what you sow: Immigration, youth, and reactive ethnicity. Applied Developmental Science 12(2), 108-111.

Ryan, A. M., Gee, G. C. \& Laflamme, D. F. (2006) The association between self-reported discrimination, physical health and blood pressure: Findings from African Americans, Black immigrants, and Latino immigrants in New Hampshire. American Journal of Health Care for the Poor and Underserved 17(2), 116-132.

Sabban, E. \& Kvetnansky, R. (2001) Stress-triggered activation of gene expression in catecholaminergic systems: Dynamics of transcriptional events. Trends in Neurosciences 24, 91-98.

Sabogal, F., Marín, G., Otero-Sabogal, R., Marín, B. V. \& Pérez-Stable, E. J. (1987) Hispanic familism and acculturation: What changes and what doesn't? Hispanic Journal of Behavioral Sciences 9(4), 397-412.

Schommer, N. C., Hellhammer, D. H. \& Kirschbaum, C. (2003) Dissociation between reactivity of the hypothalamus-pituitary-adrenal axis and the sympathetic-adrenal-medullary system to repeated psychosocial stress. Psychosomatic Medicine 65(3), 450-460.

Schulz, A. J., Israel, B. A., Zenk, S. N., Parker, E. A., Lichtenstein, R., Shellman-Weir, S. \& Klem, A. B. L. (2006) Psychosocial stress and social support as mediators of relationships between income, length of residence and depressive symptoms among African American women on Detroit's Eastside. Social Science \& Medicine 62, 510-522.

Sherwood, A., Dolan, C. A. \& Light, K. C. (1990) Hemodynamics of blood pressure responses during active and passive coping. Psychophysiology 27(6), 656-668.

Snodgrass, J. J., Sorensen, M. V., Tarskaia, L. A. \& Leonard, W. R. (2007) Adaptive dimensions of health research among indigenous Siberians. American Journal of Human Biology 19, 165-180.

Sorensen, M. V., Snodgrass, J. J., Leonard, W. R., McDade, T. W., Tarskaya, L. A., Ivanov, K. I. et al. (2009) Lifestyle incongruity, stress and immune function in indigenous Siberians: The health impacts of rapid social and economic change. American Journal of Physical Anthropology 138(1), 62-69.

Steffen, P. R. (2006) The cultural gradient: culture moderates the relationship between socioeconomic status (SES) and ambulatory blood pressure. Journal of Behavioral Medicine 29(6), 501-510.

Steffen, P. R., Smith, T. B., Larson, M. \& Butler, L. (2006) Acculturation to western society as a risk factor for high blood pressure: A meta-analytic review. Psychosomatic Medicine 68(3), 386-397.

Stephen, L. (2007) Transborder Lives: Indigenous Oaxacans in Mexico, California, and Oregon. Duke University Press, Durham, NC.

Steptoe, A., Kunz-Ebrecht, S., Owen, N., Feldman, P., Willemsen, G., Kirschbaum, C. \& Marmot, M. (2003) Socioeconomic status and stress-related biological responses over the working day. Psychosomatic Medicine 65, 461-470.

Stuber, J., Galea, S., Ahern, J., Blaney, S. \& Fuller, C. (2003) The association between multiple domains of discrimination and self-assessed health: A multilevel analysis of Latinos and blacks in four low-income New York City neighborhoods. Health Service Research 38(6 Part 2), 1735-1759.

Sweet, E., McDade, T. W., Kiefe, C. I. \& Liu, K. (2007) Relationships between skin color, income, and blood pressure among African Americans in the CARDIA Study. American Journal of Public Health 97, 2253-2259. 
Szalacha, L. A., Erkut, S., Garcia Coll, C., Fields, J. P., Alarcon, L. \& Ceder, I. (2003) Perceived discrimination and resilience. In Luthar, S. S. (ed.) Resilience and Vulnerability: Adaptation in the Context of Childhood Adversities. Cambridge University Press, Cambridge, pp. 414-435.

Tafet, G. \& Bernardini, R. (2003) Psychoneuroendocrinological links between chronic stress and depression. Progress in Neuro-Psychopharmacology and Biological Psychiatry 27, 893-903.

Tanumihardjo, S. A., Anderson, C., Kaufer-Horwitz, M., Bode, L., Emenaker, N. J., Haqq, A. M. et al. (2007) Poverty, obesity, and malnutrition: An international perspective recognizing the paradox. Journal of the American Dietetic Association 107(11), 1966-1972.

Taylor, S., Klein, L., Lewis, B., Gruenewald, T., Gurung, R. \& Updegraff, J. (2000) Biobehavioral responses to stress in females: Tend-and-befriend, not fight-or-flight. Psychological Review 107, 411-429.

Thomson, M. D. \& Hoffman-Goetz, L. (2009a) Defining and measuring acculturation: A systematic review of public health studies with Hispanic populations in the United States. Social Science \& Medicine 69, 983-991.

Thomson, M. D. \& Hoffman-Goetz, L. (2009b) Defining and measuring acculturation in public health: A response to Carter-Pokras and Bethune. Social Science \& Medicine 69, 999-1001.

Tomaka, J., Blascovich, J., Kelsey, R. M. \& Leitten, C. L. (1993) Subjective, physiological, and behavioral effects of threat and challenge appraisal. Journal of Personality and Social Psychology 65(2), 248-260.

US Census Bureau (2008a) U.S. Hispanic Population Surpasses 45 Million Now 15\% of Total. US Census Bureau News. Released: Thursday, 1st May 2008. URL: http://www.census.gov/ Press-Release/www/releases/archives/population/011910.html

US Census Bureau (2008b) Historical Income Tables - Households: Table h-8. Median Household Income by State: 1984 to 2007. Current population survey, annual social and economic supplements. URL: http://www.census.gov/hhes/www/income/histinc/h08.html (accessed 20th November 2008).

US Department of Agriculture (2005) Household Food Security in the United States. 2004/ERR11. USDA, Economic Research Service, October.

Vega, W. A. \& Gil, A. G. (1999) A model for explaining drug use behavior among Hispanic adolescents. Drugs \& Society 14(1-2), 57-74.

Villarejo, D. \& McCurdy, S. A. (2008) The California agricultural workers health survey. Journal of Agricultural Safety and Health 14(2), 135-146.

Viruell-Fuentes, E. A. (2007) Beyond acculturation: Immigration, discrimination, and health research among Mexicans in the United States. Social Science \& Medicine 65, 1524-1535.

Vozoris, N. T. \& Tarasuk, V. S. (2003) Household food insufficiency is associated with poorer health. Journal of Nutrition 133, 120-126.

Wadsworth, M. E. \& Achenbach, T. M. (2005) Explaining the link between low socioeconomic strata and psychopathology: Testing two mechanisms of the social causation hypothesis. Journal of Consulting and Clinical Psychology 73(6), 1146-1153.

Wadsworth, M. E., Raviv, T., Reinhard, C., Wolff, B., Santiago, C. D. \& Einhorn, L. (2008) An indirect effects model of the association between poverty and child functioning: The role of children's poverty-related stress. Journal of Loss and Trauma 13, 156-185.

Williams, C. \& Latkin, C. A. (2007) Neighborhood socioeconomic status, personal network attitudes, and use of heroin and cocaine. American Journal of Preventive Medicine 32(6S), S203-210.

Williams, D. R. (2008) The health of men: Structured inequalities and opportunities. American Journal of Public Health 98(9 Supplement), S150-157. 
Williams, D. R. \& Jackson, P. B. (2005) Social sources of racial disparities in health. Social Sources 24, 325-334.

Williams, D. R., Neighbors, H. W. \& Jackson, J. S. (2003) Racial/ethnic discrimination and health: Findings from community studies. American Journal of Public Health 98 (9 Supplement), S29-37. 